
MRS. VERSHA CHEED (Orcid ID : 0000-0002-6713-0913)

KHALID S KHAN (Orcid ID : 0000-0001-5084-7312)

Article type : Randomised controlled trial

\section{Pravastatin for early-onset preeclampsia: a randomized, blinded, placebo-controlled trial}

Asif $\mathrm{AHMED}^{\dagger^{*}}$, Birmingham, UK ${ }^{1,8}$;

David J WILLIAMS ${ }^{\dagger}$, London, UK²;

Versha CHEED, Birmingham, UK³;

Lee J MIDDLETON, Birmingham, UK³;

Shakil AHMAD, Birmingham, UK ${ }^{1}$;

Keqing WANG, Birmingham, UK';

Alex T VINCE, Birmingham, UK ${ }^{3}$;

Peter HEWETT, Birmingham, UK4;

Kevin SPENCER, Romford, UK5;

Khalid S KHAN, London, UK ${ }^{6}$;

Jane P DANIELS, Nottingham, UK7;

for the StAmP trial collaborative group.

tEqual contribution

${ }^{*}$ Corresponding author

1. Aston Medical Research Institute, Aston Medical School, Aston University, Birmingham, UK

This article has been accepted for publication and undergone full peer review but has not been through the copyediting, typesetting, pagination and proofreading process, which may lead to differences between this version and the Version of Record. Please cite this article as doi: 10.1111/1471-0528.16013

This article is protected by copyright. All rights reserved 
2. UCL EGA Institute for Women's Health, University College London Hospitals NHS Foundation Trust, London, UK

3. Birmingham Clinical Trials Unit, College of Medical and Dental Sciences, University of Birmingham, Birmingham, UK

4. Institute of Cardiovascular Sciences, College of Medical and Dental Sciences, University of Birmingham, UK

5. Barking, Havering \& Redbridge University Hospitals NHS Trust, Romford, UK

6. Queen Mary University of London, London, UK

7. Nottingham Clinical Trials Unit, School of Medicine, University of Nottingham, Nottingham, UK

8. King Fahad Center for Medical Research, King Abdulaziz University, Jeddah, Saudi Arabia 


\section{Running title:}

Statins to ameliorate early onset pre-eclampsia

Address for correspondence:

Prof. Asif Ahmed

Founder \& Chairman

MirZyme Therapeutics

Birmingham, B7 4BB

United Kingdom

Tel: +447973553123

Email: asif.ahmed@mirzyme.com

@ProfAsifAhmed

\section{Word count}

Abstract 241

Manuscript 


\section{ABSTRACT}

Objective: Women with preeclampsia have elevated circulating levels of soluble fms-like tyrosine kinase-1 (sFIt-1). Statins can reduce sFlt-1 from cultured cells and improve pregnancy outcome in animals with a preeclampsia-like syndrome. We investigated the effect of pravastatin on plasma sFlt-1 levels during preeclampsia.

Design: Blinded (clinician and participant), proof of principle, placebo-controlled trial Setting: 15 UK maternity units.

Population: We used a minimization algorithm to assign 62 women with early-onset preeclampsia $\left(24^{+0}-31^{+6}\right.$ weeks' gestation) to receive pravastatin $40 \mathrm{mg}$ daily $(n=30)$ or matched placebo $(n=32)$, from randomization to childbirth.

Primary outcome: Difference in mean plasma sFlt-1 levels over the first three days following randomization.

Results: The difference in the mean maternal plasma sFlt-1 levels over the first three days after randomisation between the pravastatin $(n=27)$ and placebo $(n=29)$ groups was 292pg/mL (95\%Cl: -1175- 592; $\mathrm{p}=0.5)$, and over days $1-14$ was $48 \mathrm{pg} / \mathrm{ml}(95 \% \mathrm{Cl}-1009$ to $913 ; p=0.9)$. Women who received pravastatin had a similar length of pregnancy following randomization compared with those who received placebo (Hazard ratio 0.84; 95\% Cl: $0.50-1.40 ; \mathrm{p}=0.6)$. The median time from randomization to childbirth was 9 days (IQR 5-14 days) for the pravastatin group and 7 days (IQR 4-11 days) for the placebo group. There were 3 perinatal deaths in the placebo-treated group and no deaths or serious adverse events attributable to pravastatin.

\section{Conclusions:}

We found no evidence that pravastatin lowered maternal plasma sFIt-1 levels once early onset preeclampsia had developed. Pravastatin appears to have no adverse perinatal effects.

Funding: Medical Research Council (G0701824)

Keywords: anti-angiogenic factor, double-blind, perinatal mortality, placebo-controlled, pravastatin, pre-eclampsia, randomized trial, statin.

Trial Registration: International Clinical Trial Registry Number: 23410175. www.isrctn.com/ISRCTN23410175 


\section{Tweetable abstract}

Pravastatin does not improve maternal plasma sFlt-1 or PLGF levels following a diagnosis of early pre-term preeclampsia \#clinicaltrial finds

This article is protected by copyright. All rights reserved 


\section{INTRODUCTION}

Early-onset preeclampsia affects approximately 1:200 pregnancies and is associated with serious maternal and perinatal morbidity. ${ }^{1,2}$ In low resource nations, preeclampsia accounts for one in five of all maternal and perinatal deaths. ${ }^{3}$ No agents have yet been identified that can effectively treat preeclampsia, although low dose aspirin acts as a moderately effective prophylaxis. ${ }^{4,5}$ A more effective prophylaxis against preeclampsia and a targeted therapy are desperately needed.

Preeclampsia is characterized by widespread endothelial dysfunction and is associated with loss of vascular endothelial growth factor (VEGF) activity. High circulating levels of soluble fms-like tyrosine kinase-1 (sFlt-1; also known as sVEGFR), the natural antagonist of VEGF, ${ }^{6}$ and low circulating levels of placental derived growth factor (PIGF), precede the onset of preeclampsia by several weeks. ${ }^{7,} 8$ Neutralization of excessive sFlt-1 by VEGF eliminates the signs of preeclampsia in cells ${ }^{9}$ and mice ${ }^{10}$ and extracorporeal removal of sFlt-1 in women with early-onset preeclampsia prolongs their pregnancy. ${ }^{11}$ These observations support a role for angiogenic imbalance to the 'preeclampsia phenotype'.

Statins inhibit sFlt-1 secretion from endothelial and trophoblast cells in vitro. ${ }^{12,13}$ Pregnant animals that over-express sFlt-1 from their placenta develop a preeclampsia like syndrome that is prevented by administration of pravastatin. ${ }^{14} \mathrm{We}$ therefore propose statins as a novel therapy for the treatment of preeclampsia. ${ }^{12}$

Currently statins are contraindicated in both pregnancy and lactation by the British National Formulary (BNF) and the United States Food and Drug Administration (FDA). Statins taken during pregnancy, in particular lipophilic statins, that more readily cross plasma membranes, have been linked with major congenital malformations. ${ }^{15}$ Based on the scientific rationale that statins inhibit sFlt-1 from trophoblast and endothelial cells ${ }^{12}$ and that below a critical threshold sFlt-1 fails to cause the signs of preeclampsia, ${ }^{10}$ we hypothesized that statins would ameliorate established preeclampsia. We reasoned that the potential benefit to a growth-restricted fetus of prolonging a preeclamptic pregnancy 
between $24^{+0}-31^{+6}$ weeks despite in utero exposure to a hydrophilic statin was in clinical equipoise with the potential harm of premature childbirth. There are currently no human data to support a minimum safe dose of pravastatin in pregnancy. As we were testing whether pravastatin offered a treatment effect in established early-onset preeclampsia, we chose pravastatin $40 \mathrm{mg}$ daily, the highest recommended daily dose of pravastatin outside of pregnancy. We therefore investigated whether pravastatin 40mg daily given to women with early-onset preeclampsia would reduce maternal plasma sFIt-1 levels and ameliorate their clinical condition.

\section{METHODS}

\section{Trial design}

We carried out the StAmP trial (Statins to Ameliorate Pre-Eclampsia), a double blind multicentre, placebo-controlled randomized trial in fifteen maternity units throughout the UK. All participants provided written informed consent before randomization.

\section{Study Funding and Oversight}

The study was funded by the Medical Research Council (G0701824) following a twostage peer review process.

Study oversight was provided by an independent Trial Steering Committee and an independent Data Monitoring Committee. Both committees reviewed accruing safety data during the period of recruitment on four occasions. Formal interim analysis was not undertaken. The Trial Steering Committee included a patient-parent representative from the Action on Pre-eclampsia charity.

\section{Participants and Eligibility}

Women over 18 years of age, who presented with preeclampsia between $24^{+0}$ and $31^{+6}$ weeks' of gestation, with a single viable fetus and no major anomalies were eligible for inclusion. Preeclampsia was defined by new-onset hypertension ( $>90 \mathrm{mmHg}$ diastolic) and new-onset proteinuria at $2+$ on standard urinary dipstick, confirmed by a spot protein:creatinine ratio $(\mathrm{PCR})>30 \mathrm{mg} / \mathrm{mmol}$ or $>300 \mathrm{mg}$ total protein in a 24 -hour urine sample. Women with preeclampsia superimposed on chronic hypertension were also eligible. ${ }^{16}$ Women were excluded if the attending clinician considered it unlikely that the 
pregnancy would continue for more than 48 hours after the diagnosis of preeclampsia, or were already taking statins, or had contraindications to statins.

\section{Randomization and study interventions}

Eligible, consenting women were randomized in a 1:1 ratio by a secure telephone or webbased central randomization service at the University of Birmingham Clinical Trials Unit, whereupon the trial drug pack number was not revealed until all eligibility criteria confirmed and the patient committed to the trial. Participants were randomised to receive either daily Pravastatin (40mg) or placebo of identical appearance, as a fixed dose. Trial drug was taken each evening until childbirth. Neither the clinician nor the participant were aware of the trial drug allocation. Women were expected to remain as in-patients, according to current guidelines. ${ }^{17}$ Later in the study, women with stable preeclampsia could be managed as outpatients.

A computerized minimized randomization procedure was used to achieve balance between groups for gestational age at diagnosis ( $<30$ weeks, $\geq 30+0$ weeks), smoking status (current, stopped once pregnant, never smoked) and severity of hypertension (moderate hypertension $>140 \mathrm{mmHg}$ and $<160 \mathrm{mmHg}$ systolic, or $>90 \mathrm{mmHg}$ and $<110 \mathrm{mmHg}$ diastolic; severe hypertension $\geq 160 \mathrm{mmHg}$ systolic or $\geq 110 \mathrm{mmHg}$ diastolic) and by centre.

\section{Maternal outcome measures}

The primary outcome was the mean maternal serum sFlt-1 levels during the first 3 days post randomization. Secondary anti-angiogenic outcomes were serum concentration of sFIt-1 and the sFIt-1:PIGF ratio over the first 14 days post-randomization and during the remainder of pregnancy. The main secondary clinical outcome was time from randomization to childbirth. Indicators of preeclampsia severity were blood pressure, proteinuria, serum levels of creatinine, uric acid, albumin, liver transaminases, electrolytes, platelets, and those of maternal status were prothrombin time, C-reactive protein, haemoglobin and bilirubin. 
Following recruitment, fetal wellbeing was assessed using cardiotocography, umbilical artery blood flow and amniotic fluid volume. All outcomes were considered over the first 3 days post-randomization, over 14 days and during the whole of the pregnancy. Outcomes were censored at the time of delivery.

Blood and urine samples were collected immediately before randomization, daily for the first three days post-randomization, then twice a week until the mother was discharged from hospital post-partum. Final samples were taken 6 weeks' post-partum. All biochemical parameters except s-FIt-1 and PIGF were measured locally using routine assays. An additional sample of plasma was stored locally at $-80^{\circ} \mathrm{C}$ until the women's completion of the trial, whereupon all her samples were transferred to a central laboratory. Soluble Flt-1 and PIGF were measured in a single batch-analysis using the BRAHMS Kryptor system (Thermo Fisher Scientific Inc, Germany).

\section{Neonatal outcome measures}

At birth, offspring weight, Apgar scores at 1 and 5 minutes and incidence of neonatal complications of prematurity were collected. When possible, paired maternal and umbilical cord blood was collected at childbirth for central batch quantification of Pravastatin and Pravastatin lactone using a Shimadzu Nexera XR HPLC analyzer.

Adverse events were reported by participating clinicians and were reviewed by the data monitoring committee. These were categorized under UK regulatory reporting requirements as serious adverse reactions if they resulted in maternal or fetal death or threatened the life of mother or baby, or resulted in a longer than anticipated post-natal maternal admission and were considered causally related to the study treatment, and classed as unexpected if not within the known side effect profile of pravastatin.

Outcomes were selected before the development of a core outcome set for preeclampsia.

\section{Other management of preeclampsia and timing of childbirth}

Management of preeclampsia was directed by UK guidelines for management of hypertension in pregnancy. ${ }^{17}$ Dexamethasone or Betamethasone, was given to reduce 
the risk of neonatal respiratory distress syndrome, according to the risk of imminent childbirth. The indication for childbirth was left to the judgement of individual clinicians managing preeclampsia according to UK National Institute of Health and Care Excellence guidelines. ${ }^{17}$ Drivers for childbirth included uncontrollable hypertension $(\mathrm{BP} \geq 170 / 110 \mathrm{mmHg})$, worsening maternal blood profile, a non-reassuring cardiotocograph and reversed end diastolic flow in the umbilical artery.

\section{Statistical Analysis}

According to preliminary work, we assumed the plasma level of sFlt-1 in a preeclampsia population to be approximately $6700 \mathrm{pg} / \mathrm{ml}^{7}$ To detect a one standard deviation reduction from this level (around $2100 \mathrm{pg} / \mathrm{ml}$ ) with $80 \%$ power $(\mathrm{p}=0.05)$ and assumed correlations of 0.9 (for days 1-3 measurements) and 0.1 (between baseline and post) would require 32 participants. To allow for some missing data and to increase our ability to detect difference in pre-specified subgroups the sample size was inflated to 128 participants in total. This target was later revised to 64 participants given the challenges of recruiting participants into the trial. Our ambition to undertake subgroup analyses was therefore abandoned but the other assumptions around the sample size calculation remained the same.

Primary analyses were by intention-to-treat. Continuous measures (including the primary outcome and other biochemical parameters) were compared with the use of multilevel repeated measures models, ${ }^{18}$ including parameters for group, time and baseline values. No evidence was found of any time by treatment interaction so a constant treatment effect over time was assumed in these analyses. sFIt-1, PIGF and the ratio sFIt-1:PLGF were also analysed following log transformation to account for any possibility of skewed distribution. Kaplan-Meier plots were constructed for time from randomization to childbirth; a Cox proportional hazards model was used to calculate hazard ratios. Per protocol analyses were performed to explore the effect of compliance including only those participants who remained on allocated intervention for at least three days before delivery. 
Exploratory post-hoc analyses investigated if a number of potentially prognostic variables, collected before randomization as part of the trial, had any relationship with time to delivery. The following variables (all measured on a continuous scale) were considered together in a multivariable Cox Proportional Hazard model with time delivery as the outcome: a) gestational age at diagnosis; b) systolic blood pressure; c) diastolic blood pressure; d) PIGF; e) sFlt-1; f) proteinuria/ 24 hours; g) uric acid h) platelets. In addition, i) sFIt-1/PIGF ratio was also assessed but as a replacement for d) and e). Where calculated, effect sizes are presented with $95 \%$ confidence intervals and $p$-values from two-sided tests. SAS software, version 9.4 (SAS Institute), was used for analyses.

\section{RESULTS}

\section{Patients and follow-up}

Between June 2011 and June 2014, 62 participants with early onset preeclampsia (24$31^{+6}$ weeks gestation) were randomized from 15 UK maternity units. Due to slowing recruitment rates after 33 months, we agreed with the Trial Steering Committee to set an end date of 3 years after trial start, irrespective of our target of 64 participants.

Presenting clinical features of preeclampsia, recorded before randomization, were comparable between both groups (Table 1 and Table S1). There were no maternal deaths. All 30 infants born to mothers who received pravastatin survived, whereas 29/32 infants from women who received placebo survived (Figure 1).

\section{Compliance}

Twenty-one women in each group received daily study drug until childbirth. A further four participants in the pravastatin group and one in the placebo group received at least three days of study drug, but stopped taking the drug two or more days before childbirth (Figure 1). Anti-hypertensive medication was taken by $60 / 62$ women until childbirth.

\section{Primary and biomarker outcomes}

Maternal plasma levels of sFlt-1 were lower in the pravastatin group compared with placebo, although differences were small and not statistically different over days 1-3 (292 
$\mathrm{pg} / \mathrm{ml}(95 \% \mathrm{Cl}-1175$ lower to 592 higher; $\mathrm{p}=0.5)$ and days 1-14 (48pg/ml (95\% Cl -1009 to $913 ; p=0.9$ ) (Figure $2 A)$. No differences between groups were found for maternal plasma PIGF levels nor for the sFIt-1:PIGF ratio (Figures 2B and 2C, Table 2, Table S2). There were no differences in sFIt-1 or sFIt-1:PIGF ratio between groups post-partum (Figure S1). Before randomization, women with preeclampsia who received pravastatin had lower serum sFlt-1 levels compared with those who received placebo but this difference did not reach statistical significance. Per protocol analyses and sensitivity analyses produced comparable results for each comparison (Figure S2).

\section{Clinical outcomes}

On average, pravastatin prolonged the pre-eclamptic pregnancy compared with placebo (hazard ratio $0.84 ; 95 \% \mathrm{Cl}: 0.50$ to 1.40$)$ but this difference was not significant $(p=0.6)$. The median time from randomization to childbirth was 9 days (IQR 5-14 days) for women in the pravastatin group and 7 days (IQR 4-11 days) for the placebo group. (Figure S3). Women who received pravastatin for 3 or more days as per protocol, continued their pregnancy for 11 days (IQR 6-14 days) compared with 7 days (IQR 6-11 days) for those who received placebo (HR: $0.76 ; 95 \% \mathrm{Cl} 0.41$ to $1.42 ; \mathrm{p}=0.4$ ) (Figure $\mathrm{S} 4$ ).

Maternal blood pressure and all biochemical parameters were similar between the groups over the first 3 days and up to day 14 (Table 2, Table S3). Markers of fetal growth and wellbeing, including umbilical artery pulsitility index, did not differ between groups (Table S4).

Maternal and fetal reasons for childbirth are shown in Table S5. A clinical decision to deliver the baby in response to deteriorating maternal or neonatal status was made for 29 women in the pravastatin group and 30 women in the placebo group. Other than a single participant in the placebo group, all deliveries were by caesarean section. There were no perinatal deaths in the pravastatin group, but 3 perinatal deaths in the placebo group. One baby died in utero at $26^{+4}$ weeks, another born at 26 weeks' died on day 8 from sepsis and a third neonate, born at $24^{+6}$ weeks' gestation, died on day 2 following massive pulmonary haemorrhage. 
Amongst the surviving infants, mean birth weight was $1.1 \mathrm{~kg}$ (SD 0.6) and $1.1 \mathrm{~kg}$ (SD 0.5) for babies born to mothers in the pravastatin and placebo groups, respectively). Neonatal Apgar scores were also comparable. Adverse outcomes associated with prematurity were generally comparable. However, a higher proportion of babies developed necrotizing enterocolitis in the placebo group $(n=6 ; 20 \%)$ compared with pravastatin group ( $n=3 ; 10 \%)$. Likewise, retinopathy of prematurity was more common in the placebo group ( $n=8 ; 28 \%$ ) compared with pravastatin group ( $n=4 ; 13 \%$; Table S6).

By 6 weeks post-partum, maternal blood pressure had returned to normal in both groups (pravastatin group mean blood pressure $128.1 \mathrm{mmHg}$ (SD 18.2)/80.4mmHg (SD 13.0); placebo group mean blood pressure $128.0 \mathrm{mmHg}$ (SD 13.0)/79.4mmHg (SD 11.4). Similarly, biochemical parameters had also returned to normal in both groups. (Table S7).

\section{Adverse events}

There were no serious adverse reactions considered attributable to study treatments. Serious adverse events considered unrelated to the treatment were reported in 5 women in the pravastatin group, (2 emergency deliveries for severe hypertension, one antepartum haemorrhage, one mother was readmitted post-partum with hypertension and one women who experienced post-partum psychosis. In the placebo group one women had an antepartum fever requiring hospitalization, one had a post-partum hematoma at the surgical site and three required emergency delivery due to progressive preeclampsia (Tables S5 and S6). Non-severe adverse events were indistinguishable from symptoms of preeclampsia e.g. headache, and nausea.

\section{Predictors of time to delivery}

Of the variables investigated, only PIGF (HR: $0.97 ; 95 \% \mathrm{Cl} 0.94-1.00, p=0.03)$ and the sFIt-1/PIGF ratio (HR: 1.33; 95\% Cl 1.12 - 1.57, $p=0.0009)$ were significantly associated with time from randomization to delivery, (Table S8). Results were robust to sensitivity analyses (Table S9 and S10). 


\section{Maternal transfer of pravastatin}

At the time of childbirth, paired maternal and umbilical cord blood samples were available for 18 participants in the pravastatin group and 16 in the placebo group. There was wide variability in the period between drug intake and blood collection to detect pravastatin. Women in the pravastatin treated group had plasma pravastatin levels (mean $0.86 \mathrm{ng} / \mathrm{ml}$ SD 0.58) and fetal cord blood levels (mean $0.84 \mathrm{ng} / \mathrm{ml}$ SD 1.05), which are both at the estimated assay limit for detectability for pravastatin $(0.89 \mathrm{ng} / \mathrm{ml})$. Women in the placebo group and their fetus, had circulating pravastatin levels well below the limit of detectability. (Table S11) We attempted to measure pravastatin lactone levels but the assay was unstable and could not be validated.

\section{DISCUSSION}

\section{Main Findings}

In this first randomized, placebo controlled doubled blind trial of pravastatin to ameliorate early onset preeclampsia, we found no difference in maternal plasma sFIt-1 concentration, or s-FIt-1:PIGF ratio between women who took pravastatin or placebo. Whether pravastatin $40 \mathrm{mg}$ daily for 3 days was insufficient to reduce sFlt-1 levels in women with established early-onset preeclampsia or reflects genuine therapeutic inefficacy remains uncertain. It is possible that pravastatin given as a prophylaxsis to women at risk of preeclampsia to womenmay improve the angiogenic profile and delay the clinical onset of the condition.

We showed that women with preeclampsia who received pravastatin prolonged their pregnancy by up to 4 days on average. Four days is a meaningful length of time for a fetus $<32$ weeks to mature, ${ }^{19}$ but we cannot rule out that this effect may have occurred by chance. Furthermore, preeclamptic women who received pravastatin had a lower baseline sFIt-1:PIGF ratio compared with women who received placebo. Others have shown that a high sFIt-1:PIGF ratio is associated with an increased adverse outcome and shortened time to delivery. ${ }^{20}$ Our own exploratory analyses confirmed this association, which could explain the slightly longer pregnancy duration following pravastatin treatment. When we adjusted for this baseline imbalance in sFIt-1:PIGF ratio then the 
hazard ratio for time to delivery moved to $1.07(95 \% \mathrm{Cl}: 0.61-1.88)$ from $0.84(95 \% \mathrm{Cl}$ : 0.50 to 1.40 ), although the uncertainty is such that either estimate could still not rule out benefit or harm.

We found no evidence that pravastatin had a significant impact on other maternal clinical parameters of preeclampsia. Six weeks after childbirth, all mothers in both groups had made a full clinical recovery from preeclampsia.

Adverse neonatal outcomes appeared to be less common in women who received pravastatin. None of the adverse neonatal outcomes were unexpected for neonates born as a consequence of extreme early-onset preeclampsia and differences may have occurred by chance. Our trial supports the safety of maternal pravastatin in a larger trial of women with preeclampsia or at risk of preeclampsia to improve maternal and neonatal outcomes.

\section{Strengths and Limitations}

The Stamp trial benefited from strictly concealed randomization and double-blinded drug administration across a number of sites. Recruitment was challenging, at an average of 1.4 participants per hospital per year, and the trial finished with two participants less than the revised target. The main reasons for slow recruitment were the low incidence of earlyonset preeclampsia, rapid clinical deterioration and the inability to gain informed consent to a trial of a drug that remains contraindicated in pregnancy. Greater patient and parent involvement potentially may have improved the recruitment process. The chief clinical investigator's hospital,recruited 19/62 (31\%) of study participants.

The assumption that we might observe a one standard deviation reduction in sFlt-1 over days 1-3 - equivalent to a large difference ${ }^{21}$ - may have been overoptimistic and could have diminished our ability to detect a difference between the groups.

Participants had early-onset preeclampsia according to clear and recognized criteria, although two women who had extended gestation after inclusion (one from each group) may have had gestational proteinuria and transient hypertension at presentation. Despite all participants initially managed as inpatients, compliance with the drug regime was 
lower than expected, although per protocol analyses did not suggest this had any impact on the conclusions. The decision to deliver the baby was the prerogative of the attending clinician, and we found the predominant reasons for delivery were related to deterioration in the fetal condition, which did not vary substantially between groups. The timing of cord blood venesection in relation to the last dose of pravastatin was not noted, which may explain why drug concentrations were around the lower limit of detection for the assay.

\section{Interpretation}

Before the clinical onset of pre-eclampsia there is a gradual rise in sFlt-1 levels ${ }^{8}$. Three weeks before the onset of hypertension and proteinuria, women have serum sFlt-1 levels that are $1200 \mathrm{pg} / \mathrm{ml}$ lower than at the time of diagnosis with pre-eclampsia. ${ }^{8}$ Furthermore, women with the highest mean arterial blood pressure in early pregnancy developed preeclampsia with lower levels of sFlt-1 levels ${ }^{7}$. In the Stamp trial, we could not rule out the possibility that pravastatin reduced plasma sFlt-1 levels by as much as $1175 \mathrm{pg} / \mathrm{mL}$. It is possible that this size of sFlt-1 reduction could moderate the clinical signs of preeclampsia and usefully prolong pregnancy for the benefit of fetal maturity. This possibility requires further investigation in a larger study.

One open-label trial investigated the effects of pravastatin $20 \mathrm{mg}$ daily on pregnant women with antiphospholipid antibody syndrome (APS) who developed preeclampsia between 21-30 weeks. $^{22}$ In contrast to an additional 9 (IQR 5-14) days of pregnancy in our pravastatin-treated group, these investigators found that pravastatin prolonged a preeclamptic pregnancy by a median 13 weeks (IQR 10-15 weeks). Their 10 pravastatintreated women gave birth at a median 36 weeks' gestation (IQR 35-36) and all offspring survived. Eleven further women with APS and preeclampsia did not receive pravastatin and continued their pregnancies for a median 4.5 weeks (IQR 2-6 weeks). These women gave birth at a median 26.3 (IQR 26-32) weeks gestation and only 5 infants survived. ${ }^{22}$ It is possible that pravastatin is particularly effective at ameliorating preeclampsia in women with APS. However, the non-pravastatin treated group continued their pregnancies for a further 4.5 weeks, whereas most large observational studies of early-onset preeclampsia find that expectant management prolongs pregnancy for a further 7-10 days, ${ }^{23}$ similar to the 7 (IQR 4-11) days in the placebo group of our own study. 
A pharmacokinetic study in which pravastatin $10 \mathrm{mg}$ daily was administered from the beginning of the second trimester $\left(12^{+0}-16^{+6}\right.$ weeks/gestation) to 11 women with previous early-onset preeclampsia resulted in a non-significant reduction in sFlt-1 levels compared with 10 women who received placebo. ${ }^{24}$ Similar to our study, this pharmacokinetic study found that the majority of pravastatin levels for maternal and umbilical cord samples were below the limit of quantification. ${ }^{24}$ As pravastatin has a halflife of 1.8 hours and reaches peak plasma levels around $26.5 \mathrm{ng} / \mathrm{mL}$ at 1 to 1.5 hours post oral dose, the low levels of pravastatin in maternal and cord blood, could be explained by a prolonged period of up to 24 hours from the last dose of pravastatin until childbirth. We found similar low plasma pravastatin levels in mother and fetal cord blood, which suggests transplacental passage despite the hydrophilic nature of pravastatin. However, in the study of 11 women who received pravastatin $10 \mathrm{mg}$ daily from early in the second trimester, fetal cord blood cholesterol levels at childbirth were unaltered. ${ }^{24}$

National pharmacopoeias still recommend that statins are avoided during pregnancy due to concerns about congenital anomalies and long term effects on fetal development. However, concerns about first trimester statin exposure have receded since the observation that major congenital malformations were no more common in the offspring of 1152 statin-exposed pregnant women after adjusting for pre-existing diabetes. ${ }^{25}$ Concerns about the effect of statin use throughout pregnancy on long-term childhood development remain.

Statins have pleiotropic effects beyond their beneficial effects on angiogenic factors in vitro and in animal studies. ${ }^{26}$ It remains to be investigated whether earlier use of statins might prevent or delay the onset of preeclampsia and whether pathways other than rebalancing an unfavourable angiogenic profile might be causative. Furthermore, statins are recommended for the primary prevention of cardiovascular disease,${ }^{27}$ a condition to which women with preeclampsia are predisposed. ${ }^{28}$ 


\section{Conclusions}

Pravastatin $40 \mathrm{mg}$ daily was well tolerated by women with early onset preeclampsia and had no detectable adverse effects on the short-term health of offspring. When given after the clinical diagnosis of preeclampsia, we could find no evidence that pravastatin was effective in overcoming the relentless progression of the established condition. There may be a role for statins to prevent preeclampsia in women at high risk but this remains unexplored. 


\section{ARTICLE INFORMATION}

\section{Acknowledgements}

We thank the many women who participated in the StAmP study. We also express our gratitude to our National Health Service colleagues who supported recruitment for the trial.

\section{Contribution to Authorship}

Concept and design: ASA, DJW, LJM, SA, PH, KSK, JPD

Data and trial management: ATV, JPD

Laboratory analysis: ASA, SA, KW, PH, KSK

Statistical analysis: VC, LJM

Drafting of manuscript: ASA, DJW, LJM, JPD

Critical revision of the manuscript: All authors

Obtaining funding: ASA, DJW, KSK, JPD

Supervision: ASA, DJW, JPD

DJW, JPD and LJM had full access to all of the data in the study and take responsibility for the integrity of the data and the accuracy of the data analysis.

\section{StAmP Collaborative Group}

Fifteen Recruiting Hospitals in UK (number of participants recruited) Local principal investigator, other investigator or research nurse.

Birmingham Heartlands Hospital (2) Katherine Barber; Birmingham Women's Hospital (2) Mark Kilby, Ellen Knox, Tara Sellman, Paula Trinham; Bradford Royal Infirmary (6) Derek Tuffnell, Vicky Jones, Jennifer Syson,; City Hospital, Birmingham (1) Neil Shah; Homerton University Hospital (3) Laurie Deeks, Wendy Carter, Ed Dorman, Susannah Thomas; John Radcliffe Hospital (2) Deborah Harrington, Nicola Higgins, Mirriam Wilmott-Powell; Leeds General Infirmary (2) Nigel Simpson, Vivian Dolby; Liverpool Women's Hospital (6) Leanne Bricker, Steve Walkinshaw, Gillian Houghton, Heather Longworth,; Queen Charlottes and Chelsea Hospital (6) Catherine Williamson, Mandish Dhanjal, Muna Noori, Mavis Machirori; Queens Hospital, Romford (2) Richard Howard, Rebecca Murray, Sarah Weist; Royal Infirmary Of Edinburgh; (2) Fiona Denison; Isobel Crawford, Royal Victoria Infirmary, Newcastle-upon-Tyne (3) Stephen Robson, Carly 
Allan; St Mary's Hospital, Manchester (1) Jenny Myers, Giovanna Bernatavicius, Lynsey Moorhead; St Thomas' Hospital, London (5) Lucy Chappell, Catherine Nelson-Piercy; University College Hospital (19) David Williams, Rebecca Daley, Miguel Rosas.

Trial Steering Committee: Ian Greer (obstetrics), Libor Vitek (placental biology), Andy Shennan (obstetrics), Neil Marlow (neonatology) and Ann Marie Barnard (Action on Preeclampsia charity representative).

Independent data monitoring and ethics committee: Jim Thornton (obstetrics), Janet Rennie (neonatology), Janet Peacock (statistics).

Clinical and scientific advisors: Fang Gao Smith (use of statins), Carolyn Hyde (cord blood analysis), Isobel Crawford, (research nurse) and Melissa Cudmore (biomarker development).

Past and present members of StAmP project management team at the University of Birmingham Clinical Trials Unit: Alex Furmston, Leanne Fulcher, Leanne Homer (trial management), Andrew Howman (statistics); Nicholas Hilken and Stephen Brown (database programmers).

\section{Ethical Approval}

Ethical approval was obtained from the Wales multicenter ethics committee (10/MRE09/10) on $3^{\text {rd }}$ September 2010. The study was conducted according to good clinical practice guidelines and the principles of the Declaration of Helsinki. The study sponsor was University College London.

\section{Conflict of Interest Disclosures}

The authors have declared that no potential conflicts of interest exist. Completed disclosure of interest forms are available to view online as supporting information.

\section{Sources of Funding and Support}

The study was funded by the Medical Research Council (G0701824) following a twostage peer review process and supported by Aston Medical School at Aston University. Neither the funder, the manufacturing authorization holder for pravastatin nor Thermo Fisher Scientific Inc had any role in the design and conduct of the study; collection, 
management, analysis, and interpretation of the data; preparation, review and approval of this article; and decision to submit the manuscript for publication.

DJW is supported by the National Institute for Health Research University College London Hospitals Biomedical Research Centre.

\section{Trial Protocol and Data Sharing Statement}

The final trial protocol is in Appendix S1. The data that support the findings of this study are available from the corresponding author upon reasonable request. 


\section{References}

1. Mol BW, Roberts CT, Thangaratinam S, Magee LA, de Groot CJ, and Hofmeyr GJ. Pre-eclampsia. Lancet. 2016;387(10022):999-1011.

2. Hernandez-Diaz S, Toh S, and Cnattingius S. Risk of pre-eclampsia in first and subsequent pregnancies: prospective cohort study. BMJ. 2009;338(b2255.

3. Souza JP, Gulmezoglu AM, Vogel J, Carroli G, Lumbiganon P, Qureshi Z, et al. Moving beyond essential interventions for reduction of maternal mortality (the WHO Multicountry Survey on Maternal and Newborn Health): a cross-sectional study. Lancet. 2013;381(9879):1747-55.

4. Askie LM, Duley L, Henderson-Smart DJ, and Stewart LA. Antiplatelet agents for prevention of pre-eclampsia: a meta-analysis of individual patient data. Lancet. 2007;369(9575):1791-8.

5. Rolnik DL, Wright D, Poon LC, O'Gorman N, Syngelaki A, de Paco Matallana C, et al. Aspirin versus Placebo in Pregnancies at High Risk for Preterm Preeclampsia. NEJM. 2017.

6. Ahmed A, Dunk C, Kniss D, and Wilkes M. Role of VEGF receptor-1 (Flt-1) in mediating calcium-dependent nitric oxide release and limiting DNA synthesis in human trophoblast cells. Lab Invest. 1997;76(6):779-91.

7. Noori M, Donald AE, Angelakopoulou A, Hingorani AD, and Williams DJ. Prospective study of placental angiogenic factors and maternal vascular function before and after preeclampsia and gestational hypertension. Circulation. 2010;122(5):478-87.

8. Levine RJ, Maynard SE, Qian C, Lim KH, England LJ, Yu KF, et al. Circulating angiogenic factors and the risk of preeclampsia. NEJM. 2004;350(7):672-83.

9. Ahmad S, and Ahmed A. Elevated placental soluble vascular endothelial growth factor receptor-1 inhibits angiogenesis in preeclampsia. Circulation Res. 2004;95(9):884-91.

10. Bergmann A, Ahmad S, Cudmore M, Gruber AD, Wittschen P, Lindenmaier W, et al. Reduction of circulating soluble Flt-1 alleviates preeclampsia-like symptoms in a mouse model. J Cell Mol Med. 2010;14(6b):1857-67. 
11. Thadhani R, Hagmann H, Schaarschmidt W, Roth B, Cingoez T, Karumanchi SA, et al. Removal of Soluble Fms-Like Tyrosine Kinase-1 by Dextran Sulfate Apheresis in Preeclampsia. JASN. 2016;27(3):903-13.

12. Cudmore M, Ahmad S, Al-Ani B, Fujisawa T, Coxall H, Chudasama K, et al. Negative regulation of soluble Flt-1 and soluble endoglin release by heme oxygenase-1. Circulation. 2007;115(13):1789-97.

13. Brownfoot FC, Tong S, Hannan NJ, Biner NK, Walker SP, Cannon P, et al. Effects of pravastatin on human placenta, endothelium and women with severe preeclampsia. Hypertension. 2015; 66: 687-697

14. Kumasawa K, Ikawa M, Kidoya H, Hasuwa H, Saito-Fujita T, Morioka Y, et al. Pravastatin induces placental growth factor (PGF) and ameliorates preeclampsia in a mouse model. PNAS. 2011;108(4):1451-5.

15. Edison RJ, and Muenke M. Mechanistic and epidemiologic considerations in the evaluation of adverse birth outcomes following gestational exposure to statins. Am J Med Genetics Part A. 2004;131(3):287-98.

16. Tranquilli AL, Dekker G, Magee L, Roberts J, Sibai BM, Steyn W, et al. The classification, diagnosis and management of the hypertensive disorders of pregnancy: A revised statement from the ISSHP. Pregnancy hypertension. 2014;4(2):97-104.

17. Clinical Guidelines. Hypertension in Pregnancy. London: National Institute for Health and Care Excellence; 2010.

18. Verbeke G, and Molenberghs G. Linear Mixed Models for Longitudinal Data. New York, USA: Springer-Verlag; 2000.

19. Lees CC, Marlow N, van Wassenaer-Leemhuis A, Arabin B, Bilardo CM, Brezinka $\mathrm{C}$, et al. 2 year neurodevelopmental and intermediate perinatal outcomes in infants with very preterm fetal growth restriction (TRUFFLE): a randomised trial. Lancet. 2015;385(9983):2162-72.

20. Leanos-Miranda A, Campos-Galicia I, Ramirez-Valenzuela KL, Chinolla-Arellano ZL, and Isordia-Salas I. Circulating angiogenic factors and urinary prolactin as predictors of adverse outcomes in women with preeclampsia. Hypertension. 2013;61(5):1118-25. 
21. Cohen J. Statistical power analysis for the behavioural sciences. 1977. New York: Academic Press.

22. Lefkou E, Mamopoulos A, Dagklis T, Vosnakis C, Rousso D, and Girardi G. Pravastatin improves pregnancy outcomes in obstetric antiphospholipid syndrome refractory to antithrombotic therapy. J Clin Invest. 2016;126(8):2933-40.

23. Vigil-De Gracia P, Reyes Tejada O, Calle Minaca A, Tellez G, Chon VY, Herrarte $E$, et al. Expectant management of severe preeclampsia remote from term: the MEXPRE Latin Study, a randomized, multicenter clinical trial Am J Obstet Gynaecol 2013; 209(5) 425.e1-8.

24. Costantine MM, Cleary K, Hebert MF, Ahmed MS, Brown LM, Ren Z, et al. Safety and pharmacokinetics of pravastatin used for the prevention of preeclampsia in high-risk pregnant women: a pilot randomized controlled trial. Am J Obstet Gynecol. 2016;214(6):720.e1-.e17.

25. Bateman BT, Hernandez-Diaz S, Fischer MA, Seely EW, Ecker JL, Franklin JM, et al. Statins and congenital malformations: cohort study. BMJ. 2015;350(h1035.

26. Oesterle A, Laufs $U$, and Liao JK. Pleiotropic Effects of Statins on the Cardiovascular System. Circulation research. 2017;120(1):229-43.

27. Bibbins-Domingo K, Grossman DC, Curry SJ, Davidson KW, Epling JW, Jr., Garcia FA, et al. Statin Use for the Primary Prevention of Cardiovascular Disease in Adults: US Preventive Services Task Force Recommendation Statement. JAMA. 2016;316(19):1997-2007.

28. Bellamy L, Casas JP, Hingorani AD, and Williams DJ. Pre-eclampsia and risk of cardiovascular disease and cancer in later life: systematic review and metaanalysis. BMJ. 2007;335(7627):974. 
Table 1 Characteristics of randomized women.

There were no significant difference between groups in any of these characteristics

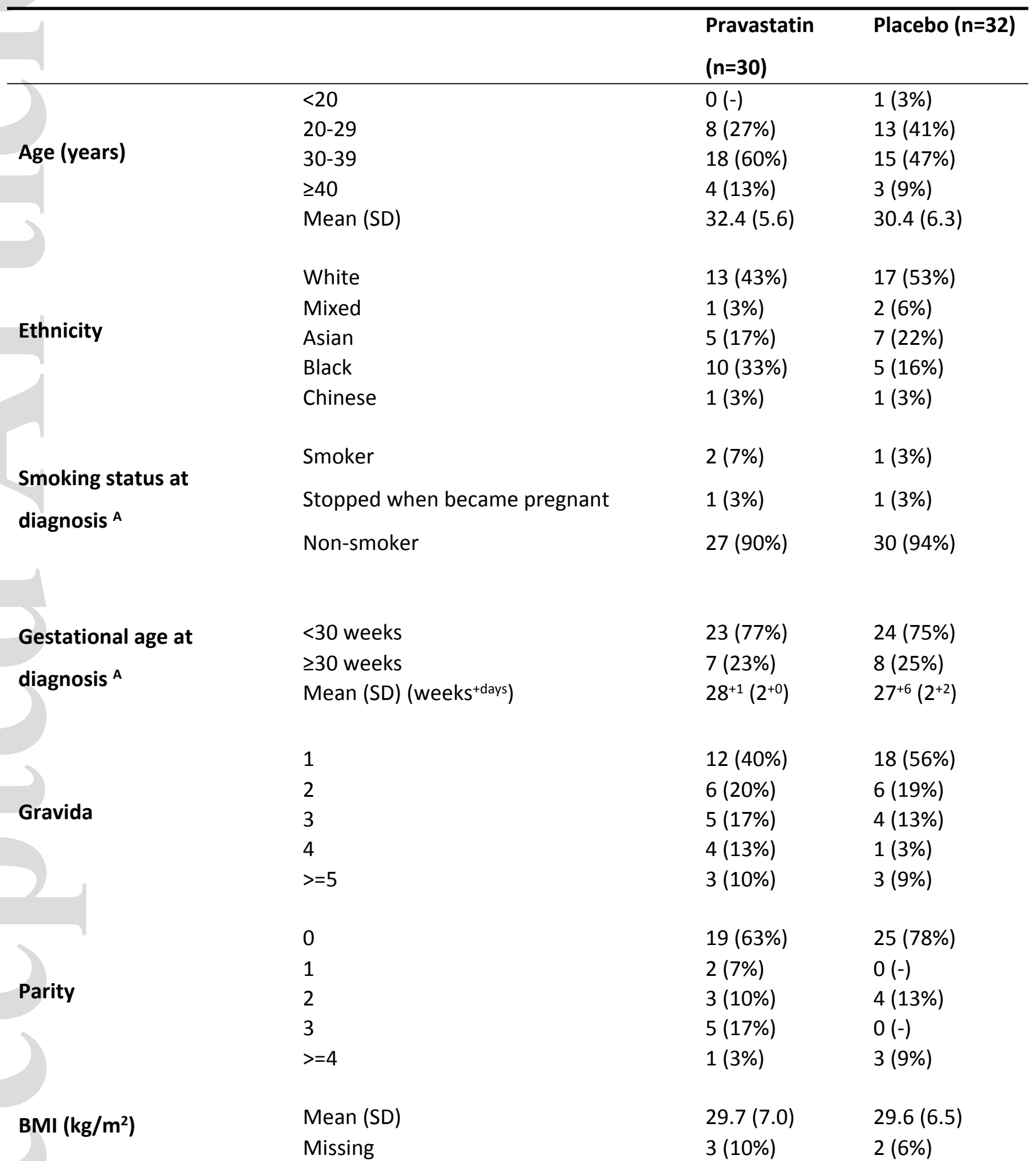

This article is protected by copyright. All rights reserved 
$>140 \mathrm{mmHg}$ systolic or

Mild $\quad 90 \mathrm{mmHg}$ diastolic but

$13(43 \%)$

$14(44 \%)$

Severity of preeclampsia ${ }^{A}$

$<160 \mathrm{mmHg}$ and

Severe

$\geq 160 \mathrm{mmHg}$ systolic or

$110 \mathrm{mmHg}$ diastolic

$17(57 \%) \quad 18(56 \%)$

Stratification

variable

and

pre-defined

sub-group

This article is protected by copyright. All rights reserved 
Table 2 Angiogenic biomarkers and other parameters of preeclampsia severity in the antepartum period - intention to treat analysis.

sFLT-1 Soluble FMS-like tyrosine kinase-1; PIGF Placental derived growth factor

\begin{tabular}{|c|c|c|c|c|c|c|c|c|c|c|c|c|c|c|}
\hline & \multicolumn{2}{|c|}{$\begin{array}{l}\text { Baseline } \\
\text { Mean (SD) }\end{array}$} & \multicolumn{2}{|c|}{$\begin{array}{c}\text { Days } 1-3^{A} \\
\text { Mean (standard } \\
\text { deviation) }\end{array}$} & \multicolumn{2}{|c|}{$\begin{array}{c}\text { Days } 4-7^{A} \\
\text { Mean (standard } \\
\text { deviation) }\end{array}$} & \multicolumn{2}{|c|}{$\begin{array}{c}\text { Days 8-14 } \\
\text { Mean (standard } \\
\text { deviation) }\end{array}$} & \multicolumn{2}{|c|}{$\begin{array}{c}\text { Days 15-21 } \\
\text { Mean (standard } \\
\text { deviation) }\end{array}$} & \multicolumn{2}{|c|}{$\begin{array}{c}\text { Days } 22-28^{\mathrm{A}} \\
\text { Mean (standard } \\
\text { deviation) }\end{array}$} & \multirow{2}{*}{\begin{tabular}{|c|} 
Difference \\
over days 1- \\
$3^{\mathrm{B}, \mathrm{D}}$ \\
Estimate \\
$(95 \% \mathrm{Cl})$
\end{tabular}} & \multirow{2}{*}{$\begin{array}{c}\text { Difference } \\
\text { over days } 1 \text { - } \\
14 \text { C,D } \\
\text { Estimate (95\% } \\
\text { CI) }\end{array}$} \\
\hline & $\begin{array}{c}\text { Pravastati } \\
n\end{array}$ & Placebo & $\begin{array}{c}\text { Pravastati } \\
n\end{array}$ & i Placebo & $\begin{array}{c}\text { Pravastati } \\
n\end{array}$ & i Placebo & $\begin{array}{c}\text { Pravastati } \\
n\end{array}$ & i Placebo & $\begin{array}{c}\text { Pravastati } \\
n\end{array}$ & i Placebo & $\begin{array}{c}\text { Pravastati } \\
n\end{array}$ & i Placebo & & \\
\hline $\begin{array}{l}\text { sFLT-1 } \\
(\mathrm{pg} / \mathrm{mL})\end{array}$ & $\begin{array}{l}N=29 \\
8296 \\
(5046)\end{array}$ & $\begin{array}{l}N=31 \\
11065 \\
(6665)\end{array}$ & $\begin{array}{l}N=27 \\
8516 \\
(4795)\end{array}$ & $\begin{array}{l}\mathrm{N}=29 \\
12241 \\
(6390)\end{array}$ & $\begin{array}{l}\mathrm{N}=19 \\
9210 \\
(5037)\end{array}$ & $\begin{array}{l}N=19 \\
10609 \\
(5367)\end{array}$ & $\begin{array}{l}\mathrm{N}=15 \\
7518 \\
(5837)\end{array}$ & $\begin{array}{l}N=108132 \\
(4050)\end{array}$ & $\begin{array}{l}N=5 \\
12811 \\
(8937)\end{array}$ & $\begin{array}{l}N=4 \quad 8458 \\
(4109)\end{array}$ & $\begin{array}{l}N=1 \\
1293(-)\end{array}$ & $\begin{array}{l}N=3 \\
12205 \\
(10341)\end{array}$ & $\begin{array}{l}-292(-1175, \\
592) p=0.5\end{array}$ & $\begin{array}{l}-49(-1010 \\
913) p=0.9\end{array}$ \\
\hline PIGF (pg/mL) & $\begin{array}{l}\mathrm{N}=29 \\
23.53 \\
(46.60)\end{array}$ & $\begin{array}{l}N=31 \\
20.37 \\
(40.33)\end{array}$ & $\begin{array}{l}\mathrm{N}=27 \\
37.17 \\
(121.40)\end{array}$ & $\begin{array}{l}\mathrm{N}=29 \\
18.67 \\
(35.27)\end{array}$ & $\begin{array}{l}\mathrm{N}=20 \\
15.98 \\
(13.04)\end{array}$ & $\begin{array}{l}\mathrm{N}=19 \\
25.39 \\
(59.77)\end{array}$ & $\begin{array}{l}N=15 \\
57.56 \\
(177.53)\end{array}$ & $\begin{array}{l}\mathrm{N}=10 \\
36.13 \\
(89.51)\end{array}$ & $\begin{array}{l}N=5 \\
82.13 \\
(150.63)\end{array}$ & $\begin{array}{l}\mathrm{N}=440.15 \\
(39.81)\end{array}$ & $\begin{array}{l}N=1 \\
528.60(-)\end{array}$ & $\begin{array}{l}N=343.84 \\
(58.80)\end{array}$ & $\begin{array}{l}8.94(-13.33 \\
31.20) p=0.4\end{array}$ & $\begin{array}{l}8.77(-11.61 \\
29.15) p=0.4\end{array}$ \\
\hline sFLT-1/PIGF & $\begin{array}{l}N=29979 \\
(1076)\end{array}$ & $\begin{array}{l}N=311782 \\
(1697)\end{array}$ & $\begin{array}{l}\mathrm{N}=27947 \\
(884)^{\mathrm{e}}\end{array}$ & $\begin{array}{l}\mathrm{N}=29 \\
2012 \\
(1779)^{\mathrm{e}}\end{array}$ & $\begin{array}{l}\mathrm{N}=19 \\
1078 \\
(940)\end{array}$ & $\begin{array}{l}N=191747 \\
(1388)\end{array}$ & $\begin{array}{l}N=15958 \\
(793)\end{array}$ & $\begin{array}{l}\mathrm{N}=101479 \\
(1228)\end{array}$ & $\begin{array}{l}N=51557 \\
(2118)\end{array}$ & $\begin{array}{l}N=4653 \\
(756)\end{array}$ & $N=1 \quad 2(-)$ & $\begin{array}{l}N=32361 \\
(3696)\end{array}$ & $\begin{array}{l}-37(-364 \\
291) p=0.8\end{array}$ & $\begin{array}{l}-54(-364,255) \\
p=0.7\end{array}$ \\
\hline $\begin{array}{l}\text { Blood } \\
\text { pressure } \\
\text { (systolic/ }\end{array}$ & $\begin{array}{l}N=30 \\
159.9 \\
(15.6) /\end{array}$ & $\begin{array}{l}\mathrm{N}=32 \\
167.1 \\
(18.3) / 99 .\end{array}$ & $\begin{array}{l}\mathrm{N}=29 \\
146.6 \\
(16.3) /\end{array}$ & $\begin{array}{l}N=31 \\
145.4(11.8 \\
) / 89.4\end{array}$ & $\begin{array}{l}N=24 \\
140.8 \\
(8.9) /\end{array}$ & $\begin{array}{l}N=24 \\
146.9 \\
(11.8) /\end{array}$ & $\begin{array}{l}N=16 \\
145.3 \\
(11.8) /\end{array}$ & $\begin{array}{l}N=13 \\
147.0 \\
(15.3) /\end{array}$ & $\begin{array}{l}\mathrm{N}=5 \\
137.1 \\
(17.8) /\end{array}$ & $\begin{array}{l}N=5138.6 \\
(8.2) / 84.7 \\
(9.4)\end{array}$ & $\begin{array}{l}\mathrm{N}=1 \\
135.5(-) / \\
75.8(-)\end{array}$ & $\begin{array}{l}\mathrm{N}=4151.2 \\
(22.6) / \\
91.2\end{array}$ & $\begin{array}{l}\text { Systolic -1.4 (- } \\
8.6,5.7) \\
\text { Diastolic -1.0 }\end{array}$ & $\begin{array}{l}\text { Systolic }-0.5 \text { (- } \\
6.0,5.0) \\
\text { Diastolic }-2.0\end{array}$ \\
\hline
\end{tabular}

This article is protected by copyright. All rights reserved 


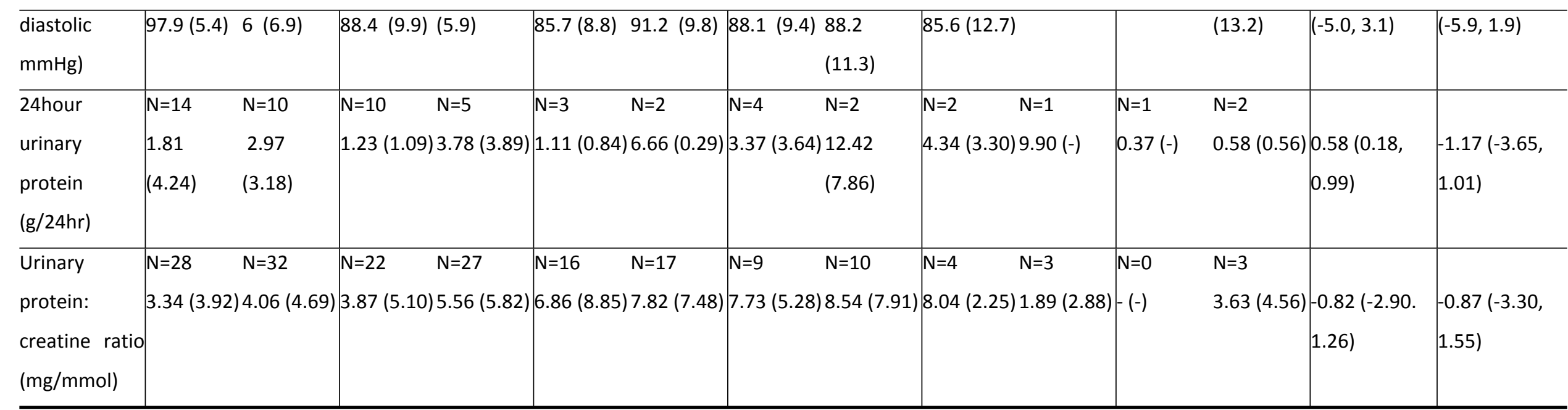

A Mean is taken for each patient with any daily value available in the respective time period. The group mean and standard deviation is then generated from these means.

${ }^{\text {B }}$ Mean difference and $95 \%$ confidence interval taken from a repeated measures analysis incorporating values taken on days 1-3, adjusting for baseline score.

c Mean difference and 95\% confidence interval taken from a repeated measures analysis incorporating values taken on days 1-14, adjusting for baseline score.

${ }^{D}$ Negative mean differences suggest biochemical parameter in the pravastatin group is generally lower than in the placebo group. 
Figure 1 Patient flow through the StAmP Trial.

Compliance categorization:

Complete: took study drug all days before delivery or ceased on day of delivery

Partial: stopped taking study drug before delivery, or took study drug intermittently, but took study drug on days 1-3 from randomization

Poor: took study drug for 0-2 days but pregnancy maintained $\geq 3$ days

Rapid delivery: took study drug for 0-2 days, pregnancy ended by day 3 .

This article is protected by copyright. All rights reserved 
Figure 2 Repeated measures analysis of s-FLT-1, PIGF and sFLT-1: PIGF during pregnancy and postrandomization, intention to treat analysis.
A: Soluble FMS-like tyrosine kinase-1 (sFlt-1)
B: Placental-derived growth factor (PIGF)
C: Ratio Soluble FMS-like tyrosine kinase-1: Placental-derived Growth Factor (sFIt-1:PIGF)

A mean is taken for each patient with any daily value within 1-3 days, 4-7 days and 8-14 days.

This article is protected by copyright. All rights reserved 


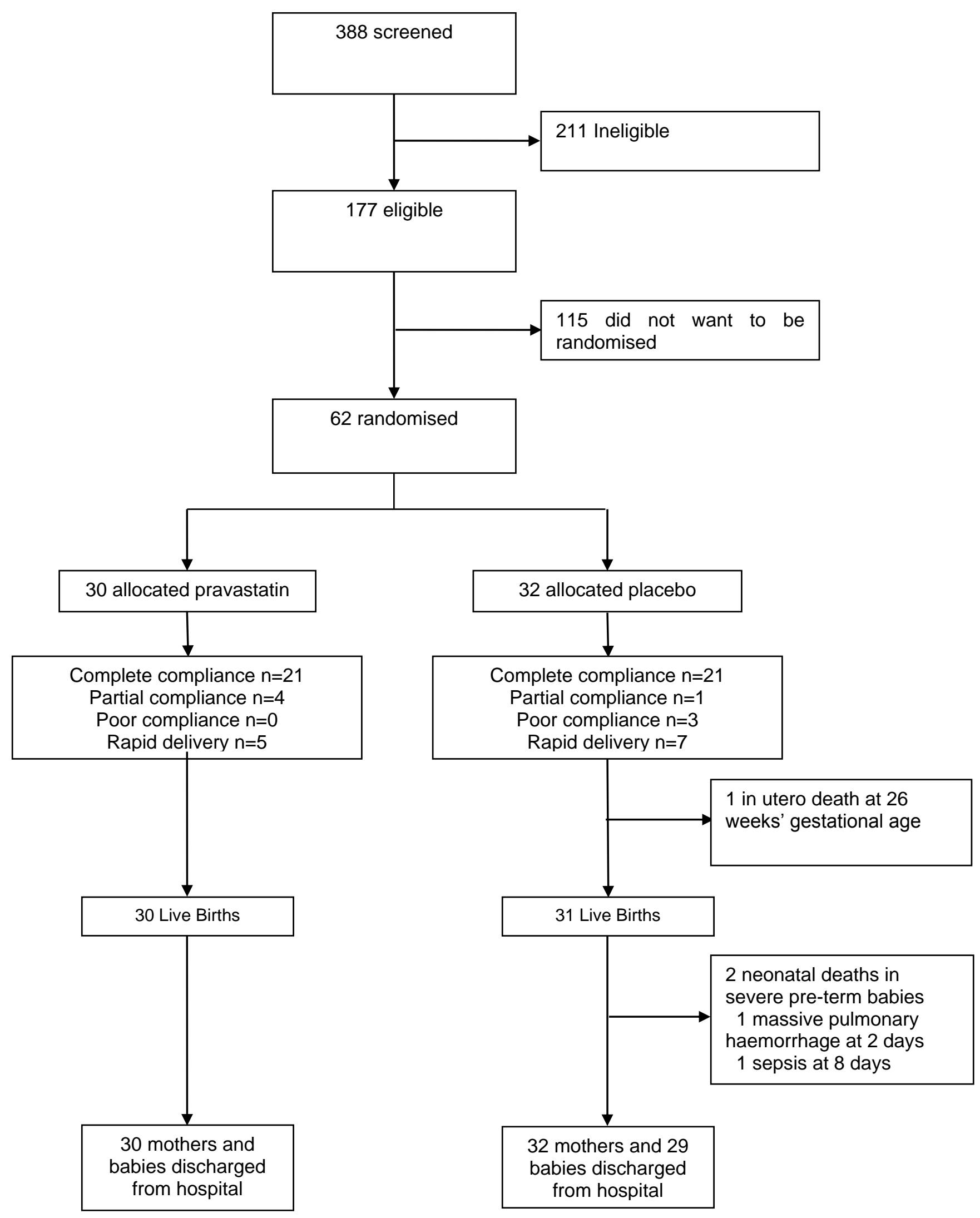


Figure 2 Repeated measures analysis of s-FLT-1, PIGF and sFLT-1: PIGF during pregnancy and postrandomisation, intention to treat analysis
A: Soluble FMS-like tyrosine kinase-1 (sFlt-1)
B: Placenta-derived Growth Factor (PIGF)
C: Ratio Soluble FMS-like tyrosine kinase-1: Placenta-derived Growth Factor (sFIt-1:PIGF)

A.

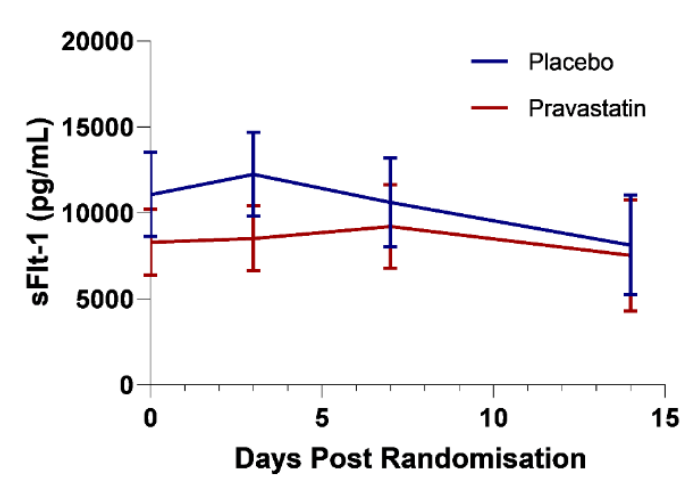

B.

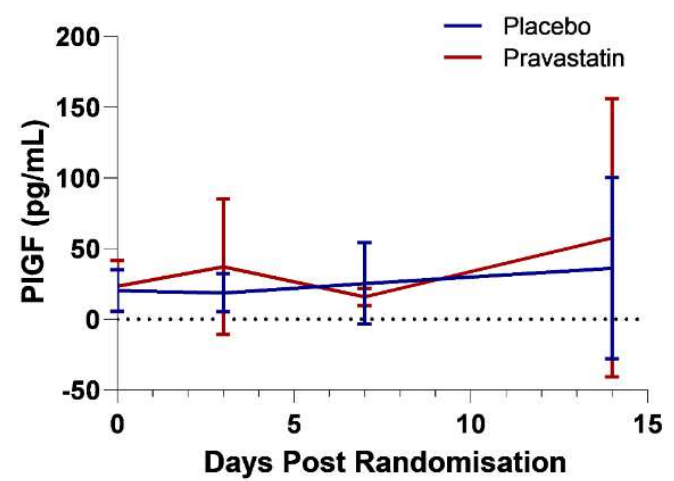

C.

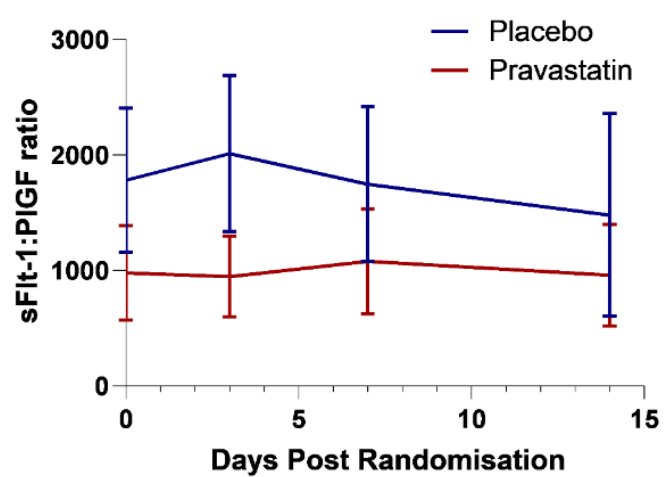

\section{Footnote:}

A mean is taken for each patient with any daily value within 1-3 days, 4-7 days and 8-14 days. Mean and $95 \%$ confidence intervals shown at each time-point. 